\title{
Proposed Update to the Taxonomy of Pestiviruses: Eight Additional Species within the Genus Pestivirus, Family Flaviviridae
}

\author{
Alexander Postel ${ }^{1}$ (D), Donald B. Smith ${ }^{2}$ and Paul Becher 1,*(D) \\ 1 Institute of Virology, University of Veterinary Medicine, 30559 Hannover, Germany; \\ alexander.postel@tiho-hannover.de \\ 2 Nuffield Department of Experimental Medicine, University of Oxford, Peter Medawar Building, \\ South Parks Road, Oxford OX1 3SY, UK; donald.smith@ndm.ox.ac.uk \\ * Correspondence: paul.becher@tiho-hannover.de; Tel.: +49-511-953-8840
}

Citation: Postel, A.; Smith, D.B.; Becher, P. Proposed Update to the Taxonomy of Pestiviruses: Eight Additional Species within the Genus Pestivirus, Family Flaviviridae. Viruses 2021, 13, 1542. https://doi.org/ $10.3390 /$ v13081542

Academic Editor:

Helle Bielefeldt-Ohmann

Received: 18 June 2021

Accepted: 2 August 2021

Published: 4 August 2021

Publisher's Note: MDPI stays neutral with regard to jurisdictional claims in published maps and institutional affiliations.

Copyright: (c) 2021 by the authors. Licensee MDPI, Basel, Switzerland. This article is an open access article distributed under the terms and conditions of the Creative Commons Attribution (CC BY) license (https:/ / creativecommons.org/licenses/by/ $4.0 /)$.

\begin{abstract}
Pestiviruses are plus-stranded RNA viruses belonging to the family Flaviviridae. They comprise several important pathogens like classical swine fever virus and bovine viral diarrhea virus that induce economically important animal diseases. In 2017, the last update of pestivirus taxonomy resulted in demarcation of 11 species designated Pestivirus A through Pestivirus K. Since then, multiple new pestiviruses have been reported including pathogens associated with disease in pigs or small ruminants. In addition, pestivirus sequences have been found during metagenomics analysis of different non-ungulate hosts (bats, rodents, whale, and pangolin), but the consequences of this pestivirus diversity for animal health still need to be established. To provide a systematic classification of the newly discovered viruses, we analyzed the genetic relationship based on complete coding sequences (cds) and deduced polyprotein sequences and calculated pairwise distances that allow species demarcation. In addition, phylogenetic analysis was performed based on a highly conserved region within the non-structural protein NS5B. Taking into account the genetic relationships observed together with available information about antigenic properties, host origin, and characteristics of disease, we propose to expand the number of pestivirus species to 19 by adding eight additional species designated Pestivirus L through Pestivirus $S$.
\end{abstract}

Keywords: Flaviviridae; pestivirus; taxonomy; species; genetic distances; phylogenetic analysis

\section{Introduction}

Pestiviruses are RNA viruses belonging to the family Flaviviridae and comprise pathogens of livestock like classical swine fever virus (CSFV) and bovine viral diarrhea virus (BVDV) that cause diseases of outstanding economic relevance notifiable to the World Organization for Animal Health (OIE) [1-3]. In early 2000, the genus Pestivirus included the four species Border disease virus, Bovine viral diarrhea virus 1, Bovine viral diarrhea virus 2, and Classical swine fever virus; the 'giraffe' pestivirus was then unclassified $[4,5]$. Subsequently, additional pestiviruses were discovered in domestic and wild animals, including HoBilike pestiviruses from cattle and buffalo [6,7]; pronghorn antelope virus from a diseased antelope in the USA [8,9]; the unique Bungowannah virus isolated from a pig farm in Australia [10]; Aydin-like pestiviruses from sheep and goats in Turkey [11,12], recently also identified in cattle [13]; and atypical porcine pestivirus that is today well-known as a major cause of congenital tremor in newborn piglets worldwide [14-18]. In many cases, these new pestiviruses are associated with abortion, still birth, or health problems of offspring. Due to the ability of pestiviruses to establish persistent infections after intrauterine infection, persistently infected hosts (including wild animals) can play an important role as virus reservoirs [19]. For many decades, it was believed that pestiviruses only infect cloven-hoofed animals. However, in the past decade, several metagenomics studies 
have discovered pestivirus genomes in non-ungulate host species; these sequences are rarely associated with virus isolation, and associations with disease are unknown [20-25]. It will be of great interest to study the host range, prevalence, geographic distributions, and other aspects of the biology of these novel viruses and to elucidate their potential as newly emerging pathogens in farm and wild animals. Due to the increasing number of diverse pestiviruses, the taxonomy of the genus Pestivirus was revised in 2017 [26] based on nucleotide or amino acid sequence distances of complete coding sequences (cds), in combination with antigenic differences, natural host range, and pathology [27]. In consequence, pestiviruses are currently classified into 11 species designated Pestivirus $A$ through Pestivirus K (Table 1).

Table 1. Established pestivirus species and reference sequences.

\begin{tabular}{|c|c|c|c|c|c|c|c|}
\hline \multirow{2}{*}{ Species } & \multirow{2}{*}{ Virus Name } & \multirow{2}{*}{ Abbreviation ${ }^{1}$} & \multirow{2}{*}{ Host Species } & \multirow{2}{*}{$\begin{array}{l}\text { Reference } \\
\text { Isolate }\end{array}$} & \multicolumn{3}{|c|}{ Reference Sequence } \\
\hline & & & & & GenBank & Length [b] & Reference \\
\hline Pestivirus A & $\begin{array}{l}\text { bovine viral } \\
\text { diarrhea } \\
\text { virus-1 }\end{array}$ & BVDV-1 & $\begin{array}{c}\text { Bos sp., Ovis spp., } \\
\text { Capra spp., } \\
\text { Artiodactyla }\end{array}$ & $\begin{array}{l}\text { SD-1 NADL } \\
\text { (cp) }\end{array}$ & $\begin{array}{l}\text { M96751 } \\
\text { M31182 }\end{array}$ & $12,30812,573$ & {$[28,29]$} \\
\hline Pestivirus $B$ & $\begin{array}{l}\text { bovine viral } \\
\text { diarrhea } \\
\text { virus-2 }\end{array}$ & BVDV-2 & $\begin{array}{c}\text { Bos sp., Ovis spp., } \\
\text { Capra spp., } \\
\text { Artiodactyla }\end{array}$ & XJ-04 890 & $\begin{array}{l}\text { FJ527854 } \\
\text { U18059 }\end{array}$ & $12,28412,513$ & Gen-Bank, [30] \\
\hline Pestivirus C & $\begin{array}{l}\text { classical swine } \\
\text { fever virus }\end{array}$ & CSFV & Sus scrofa & Alfort/187 & NC038912 & 12,298 & {$[31]$} \\
\hline Pestivirus D & $\begin{array}{l}\text { border disease } \\
\text { virus }\end{array}$ & BDV & $\begin{array}{l}\text { Ovis spp., Capra } \\
\text { spp., } \\
\text { Artiodactyla }\end{array}$ & X818 & NC003679 & 12,333 & {$[32]$} \\
\hline Pestivirus E & $\begin{array}{l}\text { pronghorn } \\
\text { antelope } \\
\text { pestivirus }\end{array}$ & PHV & $\begin{array}{l}\text { Antilocapra } \\
\text { americana }\end{array}$ & & NC024018 & 12,273 & [8] \\
\hline Pestivirus F & $\begin{array}{c}\text { porcine } \\
\text { pestivirus }\end{array}$ & BuPV & Sus scrofa & Bungowannah & NC023176 & 12,656 & {$[10]$} \\
\hline Pestivirus G & $\begin{array}{c}\text { giraffe } \\
\text { pestivirus }\end{array}$ & - & $\begin{array}{c}\text { Bos taurus, Giraffa } \\
\text { camelo-pardalis }\end{array}$ & PG-2 H138 (cp) & $\begin{array}{c}\text { KJ660072 } \\
\text { NC003678 }\end{array}$ & $12,26412,602$ & {$[33,34]$} \\
\hline Pestivirus $H$ & $\begin{array}{l}\text { HoBi-like } \\
\text { pestivirus }\end{array}$ & HoBi & Bos sp. & $\begin{array}{c}\text { Th/04_- } \\
\text { KhonKaen }\end{array}$ & NC012812 & 12,337 & [35] \\
\hline Pestivirus I & $\begin{array}{l}\text { Aydin-like } \\
\text { pestivirus }\end{array}$ & - & $\begin{array}{c}\text { Ovis spp., Capra } \\
\text { spp., } \\
\text { Bos taurus }\end{array}$ & 04-TR & NC018713 & 12,292 & [11] \\
\hline Pestivirus J & rat pestivirus & $\mathrm{NrPV}$ & Rattus norvegicus & NYC-D23 & NC025677 & $12,983^{2}$ & {$[20]$} \\
\hline Pestivirus K & $\begin{array}{l}\text { atypical } \\
\text { porcine } \\
\text { pestivirus }\end{array}$ & APPV & Sus scrofa & 515 & NC038964 & $11,276^{2}$ & [14] \\
\hline
\end{tabular}

cp: cytopathic; ${ }^{1}$ Virus names and virus abbreviations are not official ICTV designations. Given is the first proposed or commonly used abbreviation; ${ }^{2}$ complete polyprotein encoding sequence.

In the present study, the same criteria for species demarcation [26] were applied to classify recently discovered pestiviruses resulting in a proposed update of the taxonomy of the genus Pestivirus. Based on a systematic analysis of pairwise genetic distances among the complete coding sequences of representatives of the 11 established species and recently reported pestiviruses, together with the available data characterizing these viruses, we propose that eight additional species (Pestivirus $L$ through Pestivirus $S$ ) should be added to the genus Pestivirus.

\section{Materials and Methods}

Analysis of the genetic relationship between different pestiviruses was performed as previously proposed by the Flaviviridae Study Group of the ICTV [26]. Briefly, cds and deduced polyprotein sequences were aligned with MUSCLE (Neighbour joining algorithm), and pairwise distances ( $\mathrm{p}$-distances) were calculated with the tools implemented in MEGA 
$X$ (Version 10.0.5) [36]. The previously established set of 67 representative sequences of the approved species Pestivirus A through Pestivirus $K$ was used [26]. For atypical porcine pestivirus (APPV, Pestivirus K), the number of available complete coding sequences has increased from six to 69 , and in order to reflect this increased diversity, eight genetically distinct sequences were added to the previously used sequence data set (Table 2).

Table 2. GenBank accession numbers of reference sequences.

\begin{tabular}{cl}
\hline \multicolumn{1}{c}{ Species } & \multicolumn{1}{c}{ GenBank Acc. No. of Virus Sequences Used } \\
\hline \multirow{2}{*}{ Pestivirus A } & JN400273, AF526381, KX987157, M96751, AB078950, LT631725, KF896608, \\
& $\begin{array}{l}\text { KP313732, KX577637, KP941591, JQ799141, KC757383, LC089876, } \\
\text { KC853441 }\end{array}$ \\
\hline \multirow{2}{*}{ Pestivirus B } & $\begin{array}{l}\text { LC006970, KT875169, FJ527854, GQ888686, KX096718, KJ000672, } \\
\text { AB567658, AF002227, KT832818, HQ258810, JF714967 }\end{array}$ \\
\hline Pestivirus C & X87939, AY646427, KF669877, J04358, KC851953, AF407339, KJ619377, \\
& FJ529205, GQ923951, KU504339, KP233070, KM362426 \\
\hline Pestivirus D & AF037405, AB897785, U70263, KJ463422, KC963426, KF918753, \\
& GU270877, KF925348, AF144618 \\
\hline Pestivirus E & AY781152 \\
\hline Pestivirus F & EF100713 \\
\hline Pestivirus G & AF144617, KJ660072 \\
\hline Pestivirus H & FJ040215, KC297709, JX469119, JX985409, AB871953, KC788748, \\
& HQ231763, JQ612704 \\
\hline Pestivirus I & KM408491, JX428945 \\
\hline Pestivirus J & KJ950914 \\
\hline Pestivirus K & KU041639, KX77872, KR011347, KX929062, KU194229, LT594521, \\
& MN099169, MH885413, MH499646, MH307700, KY475593, MH499642, \\
& MH493896, MK216752 \\
\hline
\end{tabular}

To identify novel pestivirus sequences, a GenBank search was performed using the search term 'Pestivirus 5000[SLEN]:20000[SLEN]' on 8 January 2021 as described earlier [26]. The search resulted in 785 sequences entries. The dataset was reduced by discarding entries containing names of established species and artificial sequences e.g., related to patents. One sequence was excluded that was identified in a metagenomics approach investigating viromes of ticks. Although this virus is most closely related to pestiviruses, it shares less than $30 \%$ identity to the highly conserved pestiviral non-structural proteins NS3 and NS5 and thus likely represents a new genus within the family Flaviviridae [37]. In total, 17 novel pestivirus sequences were identified with a length of more than 5000 nucleotides (Table 3). In addition, we added the complete genome sequences of the pestivirus isolate 92019/2007/AG (GenBank MZ664274) and the closely related cds of 70282/2007/EN (GenBank MZ664273) obtained from sheep and goat in Sicily, Italy (Table 3). Previous analysis of partial $5^{\prime}$ NTR and complete $\mathrm{N}^{\text {pro }}$ coding sequences showed that both of these virus isolates belong to a group of Tunisian sheep pestivirus-like viruses (TSV) [38] Establishment of the complete genomic sequences of the two TSV isolates is described elsewhere [39]. 
Table 3. Recently reported pestivirus sequences.

\begin{tabular}{|c|c|c|c|c|c|c|c|c|}
\hline \multirow{2}{*}{$\begin{array}{l}\text { Proposed } \\
\text { Species }\end{array}$} & \multirow{2}{*}{ Virus Name } & \multirow{2}{*}{$\underset{1}{\text { Abbreviation }}$} & \multirow{2}{*}{$\begin{array}{c}\text { Host } \\
\text { Species }\end{array}$} & \multirow{2}{*}{ Isolates } & \multicolumn{3}{|c|}{ Available Sequences } & \multirow{2}{*}{ Ref. } \\
\hline & & & & & GenBank & Region & Length $[b]$ & \\
\hline Pestivirus L & Linda virus & LindaV & Sus scrofa & Austria1 & NC035432 & genome & 12,614 & [40] \\
\hline \multirow{3}{*}{ Pestivirus $M$} & \multirow{3}{*}{$\begin{array}{l}\text { Phocoena } \\
\text { pestivirus }\end{array}$} & \multirow{3}{*}{ PhoPeV } & \multirow{3}{*}{$\begin{array}{l}\text { Phocoena } \\
\text { phocoena }\end{array}$} & PhoPeV-1 & MK910227 & genome & 11,880 & [22] \\
\hline & & & & PhoPeV-2 & MK910228 & genome & 11,880 & [22] \\
\hline & & & & PhoPeV-3 & MK910229 & genome & 12,060 & {$[22]$} \\
\hline \multirow[t]{2}{*}{ Pestivirus N } & \multirow{2}{*}{$\begin{array}{l}\text { Tunisian } \\
\text { sheep-like } \\
\text { pestivirus }\end{array}$} & \multirow[t]{2}{*}{ TSV } & $\begin{array}{c}\text { Capra } \\
\text { aegagrus } \\
\text { hircus }\end{array}$ & \multirow{2}{*}{\multicolumn{2}{|c|}{ 70292/2007/ENMZ664273 }} & cds & 12,268 & [39] \\
\hline & & & $\begin{array}{l}\text { Ovis gmelini } \\
\text { aries }\end{array}$ & & & genome & 12,286 & [39] \\
\hline \multirow{3}{*}{ Pestivirus $O$} & \multirow{3}{*}{$\begin{array}{l}\text { ovine/IT } \\
\text { pestivirus }\end{array}$} & \multirow{3}{*}{ ovIT PeV } & \multirow{3}{*}{$\begin{array}{l}\text { Ovis gmelini } \\
\text { aries }\end{array}$} & $\begin{array}{l}338710- \\
2 / 2017\end{array}$ & MK618725 & partial & 11,143 & [41] \\
\hline & & & & $\begin{array}{l}338710- \\
3 / 2017\end{array}$ & MK618726 & cds & 12,173 & [41] \\
\hline & & & & $1756 / 2017$ & MG770617 & cds & 12,173 & [41] \\
\hline \multirow[t]{2}{*}{ Pestivirus $P$} & \multirow{2}{*}{$\begin{array}{l}\text { pangolin } \\
\text { pestivirus }\end{array}$} & \multirow[t]{2}{*}{ DYPV } & \multirow{2}{*}{$\begin{array}{c}\text { Amblyomma } \\
\text { javanense } \\
\text { Manis } \\
\text { javanica }\end{array}$} & DYAJ1 & MK636874 & genome & 12,443 & [21] \\
\hline & & & & DYCS & MK636875 & genome & 12,446 & [21] \\
\hline Pestivirus $Q$ & $\begin{array}{c}\text { rodent } \\
\text { pestivirus }\end{array}$ & RtNn-PeV & $\begin{array}{l}\text { Niviventer } \\
\text { niviventer }\end{array}$ & HuB2014 & KY370101 & cds & 13,220 & [24] \\
\hline Pestivirus $R$ & $\begin{array}{c}\text { rodent } \\
\text { pestivirus }\end{array}$ & RtAp-PeV & $\begin{array}{l}\text { Apodemus } \\
\text { peninsulae }\end{array}$ & JL2014 & KY370100 & cds & 12,768 & [24] \\
\hline n.a. & $\begin{array}{c}\text { rodent } \\
\text { pestivirus }\end{array}$ & RtNe-PeV & $\begin{array}{l}\text { Niviventer } \\
\text { excelsior }\end{array}$ & SC2014 & KY370099 & partial & 11,644 & [24] \\
\hline n.a. & $\begin{array}{c}\text { rodent } \\
\text { pestivirus }\end{array}$ & RtAd-PeV & $\begin{array}{l}\text { Apodemus } \\
\text { draco }\end{array}$ & SAX2015 & KY370102 & partial & 11,551 & [24] \\
\hline n.a. & $\begin{array}{c}\text { rodent } \\
\text { pestivirus }\end{array}$ & RtNn-PeV & $\begin{array}{l}\text { Niviventer } \\
\text { niviventer }\end{array}$ & SAX2015 & KY370103 & partial & 11,435 & [24] \\
\hline Pestivirus S & bat pestivirus & \multirow{3}{*}{ BtSk-PeV } & \multirow{3}{*}{$\begin{array}{c}\text { Scotophilus } \\
\text { kuhlii }\end{array}$} & 1/GX2017 & MH282908 & cds & 11,921 & [23] \\
\hline n.a. & bat pestivirus & & & 3/GX2017 & MH282910 & partial & 7266 & {$[23]$} \\
\hline n.a. & bat pestivirus & & & 4/GX2017 & MH282911 & partial & 7132 & [23] \\
\hline
\end{tabular}

n.a., not assigned (no complete cds available); ${ }^{1}$ Virus names and virus abbreviations are not official ICTV designations. Given is the first proposed or commonly used abbreviation.

For phylogenetic analysis, amino acid sequences of a conserved region of NS5B corresponding to positions 3312-3837 in the polyprotein of BVDV-1 (Pestivirus A) reference strain SD-1 were compared (Figure 1A). Maximum likelihood trees were generated using the complete cds (Figure 1B) and polyprotein amino acid sequences (Figure 1C). Phylogenetic analysis of the NS5B region served as one criterion for the last update of pestivirus taxonomy, which resulted in the approval of the 11 species [26]. Multiple sequence alignment was performed using MUSCLE, and phylogenetic trees were generated by maximum likelihood applying the JJT model as implemented in MEGA X [36]. To reduce the size of the tree, two redundant sequences were discarded (GenBank MK618726, MK910229) and clades including multiple sequences of BVDV-1 (Pestivirus A), BVDV-2 (Pestivirus B), CSFV (Pestivirus C), BDV (Pestivirus D), HoBi-like pestiviruses (Pestivirus H), and APPV (Pestivirus K) were collapsed. Phylogenetic analyses based on the complete cds and polyprotein amino acid sequences were additionally performed with a reduced sequence set of CSFV (Pestivirus C), BDV (Pestivirus D), Aydin-like pestiviruses (Pestivirus I), TSV, and novel ovine pestiviruses from Italy (ovIT PeV) (Figure 1B,C). 


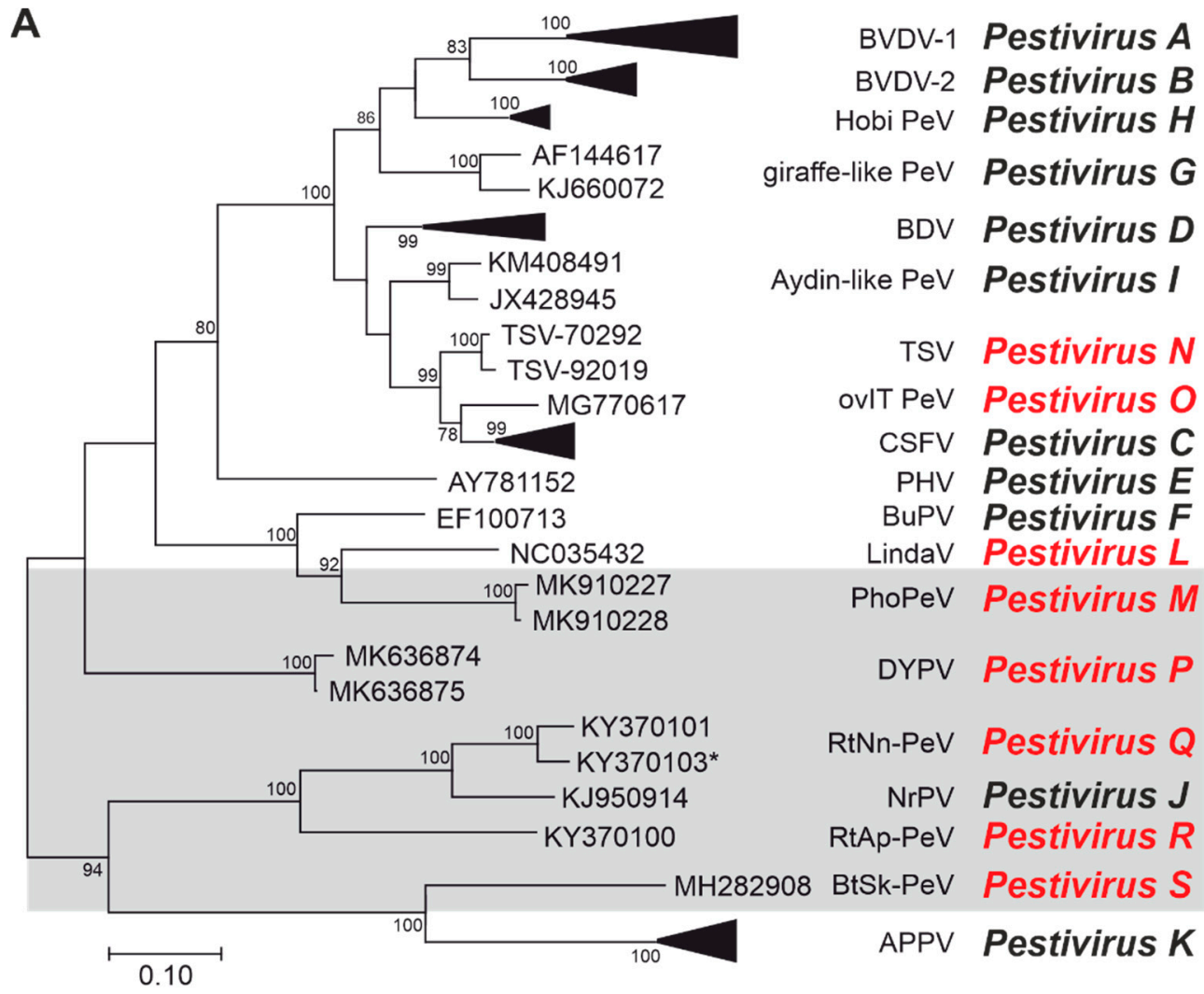

B

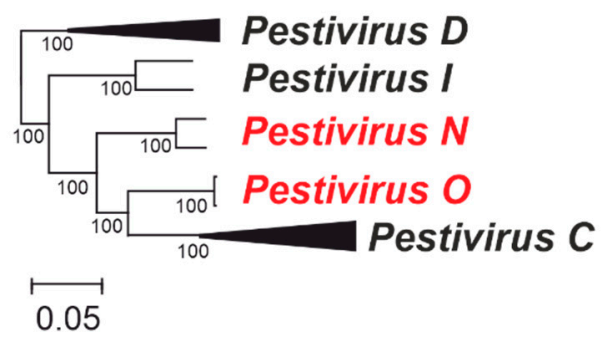

C

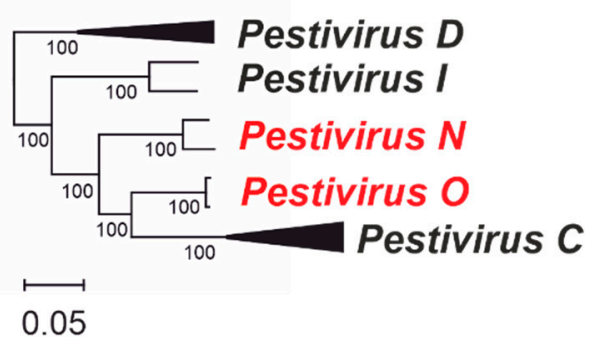

Figure 1. Phylogenetic characterization of known pestiviruses. (A) Construction of the Maximum likelihood tree was based on the conserved partial NS5B peptide sequences corresponding to positions 3312-3837 in the polyprotein of BVDV-1 (Pestivirus A) reference strain SD-1. With one exception (KY370103, indicated by asterisk), the sequences were derived from complete coding sequences. Core data set was used as established earlier and modified as described in Materials and methods [26]. Given are GenBank accession numbers and abbreviations of virus names as listed in Tables 1 and 3 . The established (Pestivirus A through Pestivirus K; black) and newly proposed (Pestivirus L through Pestivirus S; red) pestivirus species are indicated next to the tree. Pestivirus sequences identified in non-ungulate hosts are highlighted (grey shaded box). For clarity, the clades for viruses in the species Pestivirus A, Pestivirus B, Pestivirus C, Pestivirus D, Pestivirus $H$, and Pestivirus $K$ are collapsed. For statistical analysis, 1000 bootstrap repetitions were performed. Only bootstrap values $>70 \%$ are shown. A subset of pestivirus species closely related to TSV (Pestivirus N) and ovIT PeV (Pestivirus O) was analyzed separately by Maximum likelihood analyses for complete coding sequences (B) and polyprotein sequences (C) to compare the topologies of the trees.

\section{Results and Discussion}

\subsection{Update of the Reference Data Set}

The dataset previously used for pestivirus species demarcation was adjusted as the number of sequences available for APPV (Pestivirus K) has increased significantly, revealing greater genetic variation. Comparison of the cds of six APPV reference sequences used for the last update of pestivirus taxonomy in 2017 revealed p-distances on genomic nucleotide and amino acid level of $<0.13$ and $<0.06$, respectively [26]. Genetic diversity in the updated 
APPV (Pestivirus K) data set increased these to $<0.20$ and $<0.10$, respectively, similar to that observed for CSFV (Pestivirus C) (Table 4). It has been previously reported that the maximum genomic nucleotide and amino acid p-distances between members of the same species did not exceed 0.24 and 0.15 , respectively, with the highest diversity observed within BVDV-1 (Pestivirus A) and BDV (Pestivirus D) [26] (Table 4). The minimum nucleotide and amino acid p-distances between members of different species are $>0.28$ and $>0.19$ (between members of Pestivirus I and Pestivirus D, Table 5). In all cases, p-distances of the conserved NS5B peptide are less than 0.13 between members of the same species and exceed 0.13 between members of different species.

Table 4. Maximum p-distances between members of individual pestivirus species.

\begin{tabular}{ccccc}
\hline \multirow{2}{*}{ Species } & Virus Name & \multicolumn{3}{c}{ p-Distances } \\
\cline { 3 - 5 } & & CDS & Polyprotein & NS5B $_{3312-3837}$ \\
\hline Pestivirus $A$ & BVDV-1 & $<0.22$ & $<0.15$ & $<0.11$ \\
Pestivirus B & BVDV-2 & $<0.17$ & $<0.11$ & $<0.10$ \\
Pestivirus C & CSFV & $<0.19$ & $<0.13$ & $<0.07$ \\
Pestivirus D & BDV & $<0.24$ & $<0.15$ & $<0.13$ \\
Pestivirus H & HoBi & $<0.10$ & $<0.07$ & $<0.05$ \\
Pestivirus K & APPV & $<0.20$ & $<0.10$ & $<0.07$ \\
\hline
\end{tabular}

Table 5. Minimum p-distances between members of selected pestivirus species.

\begin{tabular}{|c|c|c|c|c|}
\hline \multirow{2}{*}{\multicolumn{2}{|c|}{ Species Compared }} & \multicolumn{3}{|c|}{ Minimum p-Distances } \\
\hline & & \multirow{2}{*}{$\begin{array}{c}\text { CDS } \\
>0.30\end{array}$} & \multirow{2}{*}{$\begin{array}{c}\text { Polyprotein } \\
>0.24\end{array}$} & \multirow{2}{*}{$\begin{array}{c}\text { NS5B }_{3312-3837} \\
>0.17\end{array}$} \\
\hline Pestivirus A & Pestivirus B & & & \\
\hline Pestivirus C & Pestivirus D & $>0.29$ & $>0.21$ & $>0.14$ \\
\hline Pestivirus C & Pestivirus I & $>0.28$ & $>0.20$ & $>0.14$ \\
\hline Pestivirus D & Pestivirus I & $>0.28$ & $>0.19$ & $>0.14$ \\
\hline Pestivirus L & Pestivirus F & 0.35 & 0.31 & 0.22 \\
\hline Pestivirus $M$ & $\begin{array}{l}\text { Pestivirus F, } \\
\text { Pestivirus L }\end{array}$ & $>0.37$ & $>0.36$ & $>0.22$ \\
\hline Pestivirus N & Pestivirus C & $>0.24$ & $>0.16$ & $>0.09$ \\
\hline Pestivirus N & Pestivirus I & $>0.26$ & $>0.18$ & $>0.13$ \\
\hline Pestivirus N & Pestivirus $O$ & 0.23 & $>0.14$ & 0.11 \\
\hline Pestivirus $O$ & Pestivirus C & $>0.22$ & $>0.14$ & $>0.11$ \\
\hline Pestivirus $P$ & $\begin{array}{l}\text { Pestivirus F, } \\
\text { Pestivirus M }\end{array}$ & $>0.41$ & $>0.47$ & $>0.33$ \\
\hline Pestivirus $Q$ & Pestivirus $R$ & 0.40 & 0.42 & 0.33 \\
\hline Pestivirus $Q$ & Pestivirus J & 0.30 & 0.22 & 0.17 \\
\hline Pestivirus $R$ & Pestivirus $Q$ & 0.40 & 0.42 & 0.33 \\
\hline Pestivirus $R$ & Pestivirus J & 0.40 & 0.42 & 0.31 \\
\hline Pestivirus S & Pestivirus K & $>0.40$ & $>0.40$ & $>0.29$ \\
\hline
\end{tabular}

\subsection{Recently Identified Pestiviruses Represent Novel Species}

In principle, species epithets for novel species will be capital letters given chronologically. As in this case where several species are being proposed at the same time, this allows some flexibility. Like in the last update of taxonomy, letters were chosen that evoke an association with the respective virus.

\subsubsection{Linda Virus}

Shortly after the last update of pestivirus taxonomy introducing the species names Pestivirus A through Pestivirus K, a novel pestivirus was discovered in a commercial pig farm in Austria in association with congenital tremor in newborn piglets [40]. This virus was successfully isolated on established porcine cell lines and named LINDA virus (LindaV). The complete genome sequence (GenBank NC035432) reveals that LindaV is genetically 
most closely related to Bungowannah virus (BuPV, Pestivirus F; p-distance 0.35, Table 5), which was isolated from diseased pigs in a large pig holding in Australia in 2005 [10]. Phylogenetic analysis of $\mathrm{NS5B}_{3312-3837}$ peptides of the reference set of pestivirus sequences confirmed the genetic relationship of LindaV to BuPV (Figure 1). The observation that nucleotide and amino acid distances between LindaV and BuPV (Pestivirus F) are greater than those observed between members of different existing pestivirus species (Table 5) supports the proposal of Kiesler et al. [42] that LindaV is a member of a new pestivirus species. This being the first pestivirus to be described after the establishment of Pestivirus $K$ and since the virus is called LINDA virus, we propose to name this species Pestivirus $L$. Consistent with the conclusion that it belongs to a novel species, LindaV can induce congenital tremor, which has not been reported in BuPV infected piglets [10,40]. Moreover, it has been reported that antisera obtained from pigs after acute infection with LindaV do not show cross-neutralization against BVDV-1 (Pestivirus A), BVDV-2 (Pestivirus B), CSFV (Pestivirus C), BDV (Pestivirus D), Giraffe-like pestivirus (Pestivirus G) or HoBi-like pestivirus (Pestivirus H) [42]. However, members of these different pestivirus species can be detected by the broadly cross-reactive E2-specific monoclonal antibody 6A5. This $\mathrm{mab}$ is also able to detect LindaV infections, providing evidence for a commonly shared epitope [40]. Similarly, a porcine convalescence serum that neutralized BuPV $\left(\mathrm{ND}_{50} 1 / 3200\right)$ also efficiently neutralized LindaV $\left(\mathrm{ND}_{50} 1 / 1600\right)$ in a virus neutralization test [24,42]. These cross-reactivities may cause problems in serological discrimination of pestiviruses.

\subsubsection{Phocoena Pestivirus}

In 2019, a novel pestivirus, Phocoena pestivirus (PhoPeV), was discovered in harbor porpoises (Phocoena phocoena) [22], the virus replicating in bovine (MDBK) and porcine (PK-15) cells. Genome fragments of different pestiviruses present in samples from harbor porpoises collected at the North Sea coast show a diversity of less than $10 \%$ at the nucleotide level [22]. In addition, three very similar complete genome sequences have been obtained (GenBank MK910227-29), including one that harbors a 180 nucleotide insertion within the p7-NS2 coding region (GenBank MK910229). PhoPeV is most closely related to LindaV (Pestivirus L) and-more distantly-to BuPV (Pestivirus F, Figure 1) with genomic p-distances at the nucleotide and amino acid level of $>0.37$ and $>0.36$, respectively, and

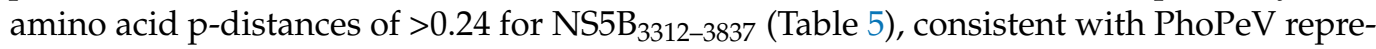
senting an additional pestivirus species. Being the first pestivirus discovered in a marine mammal, we propose to designate this species Pestivirus $M$. Uniquely among pestiviruses, all known genome sequences of PhoPeV lack the pestivirus-specific $\mathrm{N}^{\text {pro }}$ encoding sequence, possibly because of differences in the innate immune system of cetaceaen host species [22]. Sequences of the $\mathrm{E}^{\mathrm{rns}}$ protein, a second protein unique to pestiviruses, are present in the genomes of $\mathrm{PhoPeV}$ isolates. $\mathrm{PhoPeV}$ is apparently highly prevalent in the harbor porpoise population of the Dutch North Sea, providing evidence for long lasting or persistent infection as also known for biologically well characterized pestiviruses like BVDV-1 (Pestivirus A) and CSFV (Pestivirus C) [22]. So far, no information on antigenic relatedness between PhoPeV (Pestivirus $M$ ) and members of other pestivirus species has been reported.

\subsubsection{Pangolin Pestivirus}

Pestivirus sequences have been recently discovered in fatally diseased pangolins in China and named Dongyang pangolin virus (DYPV) [21]. Two very similar complete genome sequences have been obtained, but no virus isolate is available. Comparative analysis of complete coding and polyprotein sequences revealed genomic nucleotide and amino acid p-distances between DYPV and other pestiviruses of $>0.41$ and $>0.47$, respectively (Table 5). Interestingly, nucleotide p-distances are slightly lower than amino acid p-distances. Amino acid distances for NS5B $_{3312-3837}$ are $>0.33$ (Table 5), consistent with DYPV representing an additional pestivirus species. As a virus belonging to this species was first detected in samples from pangolins, we propose to name it Pestivirus $P$. 


\subsubsection{Bat Pestiviruses}

Genomic sequences of five different pestiviruses (GenBank MH282908-MH282911, JQ814854) have been detected in bats in China $(23,25)$, these being most closely related to APPV (Pestivirus K). Four sequences, including a complete cds (GenBank MH282908, BtSk-PeV-1/GX2017) obtained from a bat of the species Scotophilus kuhlii, are very similar to each other, while one partial sequence from a bat of the species Rhinolophus affinis (GenBank JQ814854) is significantly different with nucleotide p-distances of $0.34-0.36$ for the $680 \mathrm{nu}$ cleotide region corresponding to positions 4742-5421 of GenBank MH282908, much higher than among the Scotophilus kuhlii virus sequences (0.01-0.05). A similar divergence was observed for the region corresponding to positions 2444-7452 of GenBank MH282908 (distances of $0.34-0.36$ compared to $<0.02$ among three of the Scotophilus kuhlii virus sequences). Although these results are consistent with the bat pestivirus sequences belonging to two additional species, only one of these sequences is a complete genome sequence (MH282908, from Scotophilus kuhlii). Comparisons of this sequence with representatives of existing pestivirus species (Table 5) are consistent with this representing an additional species. Due to the first description of the virus from this species in samples from Scotophilus bats, it is proposed to use the designation Pestivirus $S$ for this novel species.

\subsubsection{Rodent Pestiviruses}

Rodent pestivirus sequences were first reported in a Norway rat (Rattus norvegicus) in New York City in 2014. This novel pestivirus was designated Norway rat pestivirus (NrPV) and assigned to the species Pestivirus J [20]. More recently, two complete genome sequences of pestiviruses were reported from the Chinese rodents Niviventer niviventer (GenBank KY370101) and Apodemus peninsulae (GenBank KY370100) [23,24] with minimum nucleotide and amino acid p-distances to the Norway rat pestivirus of 0.30 and 0.22 , and even higher p-distances ( 0.4 and 0.42$)$ between each other, with similar results for the $\mathrm{NS} \mathrm{B}_{3312-3837}$ region ( 0.16 to the rat pestivirus, 0.32 between each other). We propose that these represent two additional species. The species names Pestivirus $Q$ (GenBank KY370101) and Pestivirus $R$ (GenBank KY370100) are proposed with the letter " $R$ " referring to the rodent host and " $\mathrm{Q}$ " the preceding letter in the alphabet. Additional partial sequences obtained from Chinese rodents (GenBank KY370099, KY370102, KY370103) are very similar and belong to the species Pestivirus Q. Only in one case (GenBank KY370103) does the available sequence cover also the region encoding for the conserved NSB peptide, which has an amino acid p-distance of only 0.06 to the most closely related member of Pestivirus $Q$. The viruses NrPV (Pestivirus J), the novel rodent pestiviruses (Pestivirus $Q$, Pestivirus $R$ ), the bat pestivirus (Pestivirus S), and APPV (Pestivirus K) form one monophyletic clade (Figure 1). Within this clade, antigenic relationships to members of other pestivirus species have been described only for APPV (Pestivirus K) [43]. The association between virus infection and disease or pathology is known for APPV but not for other members of this clade $[15,17]$.

\subsubsection{Tunisian Sheep-Like Viruses}

Pestiviruses were discovered 20 years ago in diseased small ruminants in Tunisia $[44,45]$. These viruses were designated as Tunisian sheep-like viruses (TSV) or Tunisian small ruminant viruses (TSRV) and were subsequently also found in France and Italy $[38,46,47]$. Comparison of partial sequences showed that TSV is most closely related to CSFV (Pestivirus C) and Aydinlike pestiviruses (Pestivirus I) [12,38] (Figure 1). Phylogenetic analyses based on partial genome sequences suggested that TSV probably represents a novel pestivirus species [6,38]. Complete coding sequences were recently established for two TSV isolates [39], and comparative analysis of these sequences revealed nucleotide and amino acid p-distances of $>0.24$ and $>0.16$ to CSFV and $>0.26$ and $>0.18$ to Aydin-like pestiviruses, respectively. These p-distances are slightly higher than the respective maximum nucleotide and amino acid p-distances of $<0.24$ and $<0.15$ observed within BDV (Pestivirus D, Table 4). Analysis of partial NS5B ${ }_{3312-3837}$ sequences revealed p-distances of $>0.13$ between TSV and Aydin-like pestiviruses (Pestivirus I) and 
distances of $>0.09$ between TSV and CSFV isolates (Pestivirus $C$ ), the latter being lower than observed between members of existing species (Table 5).

According to the criteria for species demarcation defined by the ICTV Flaviviridae study group, besides the genetic relationship of viruses, the host species and the ability to cause disease are also considered in the definition of species [27]. Although TSV is genetically closely related to CSFV (Pestivirus C), the natural host range of TSV is restricted to small ruminants and it has not been identified in porcine hosts. Moreover, after experimental infection of pigs, no CSF-like symptoms were observed [39]. Taking into account these biological properties and the calculated p-distances of complete coding sequences and polyprotein sequences, it is proposed that TSV represents a separate species designated as Pestivirus N.

\subsubsection{Ovine/Italy Pestiviruses}

An additional group of pestiviruses capable of inducing Border disease-like symptoms has recently been discovered in small ruminants from Italy [41]. Analysis of the complete genome sequences of these viruses revealed a close relationship to a short partial $5^{\prime}$ NTR sequence of a pestivirus identified in 1999 in a sheep flock in Northern Spain and associated with abortion, stillbirth, and weak lambs [48]. Comparative analysis of complete coding sequences and polyprotein sequences showed that the ovine Italian pestivirus isolates (ovIT PeV, in literature also abbreviated OVPV) are closely related to CSFV (Pestivirus C) and TSV (Pestivirus N) [41]. Nucleotide and amino acid p-distances are $>0.22$ and $>0.14$ to CSFV (Pestivirus C) and 0.23 and $>0.14$ to TSV (Pestivirus N), respectively (Table 4), similar to the distances of $<0.22$ and $<0.15$ observed between sequences of BVDV-1 (Pestivirus $A$ ) or $<0.24$ and $<0.15$ between sequences of BDV (Pestivirus $D$ ). For the conserved NS5B $_{3312-3837}$ peptide sequences, $\mathrm{p}$-distances between ovIT isolates and CSFV (Pestivirus $C$ ) are higher than 0.10 and distances between ovIT isolates and TSV (Pestivirus N) are 0.11 . Thus, nucleotide and amino p-distances of complete or partial genome sequences do not clearly support the classification of ovIT into an additional species. Similarly, phylogenetic analysis of these genome regions reveal that ovIT shares a branch with CSFV (Pestivirus C, Figure 1). However, on the basis that there is no evidence for ovIT natural infection of pigs, we propose to classify ovIT pestiviruses as an additional pestivirus species. As these pestiviruses were first isolated from ovine hosts and are closely related to TSV (Pestivirus $N$ ), we propose to assign consecutive letters and name the species Pestivirus $O$.

\section{Conclusions}

In this study, we systematically analyzed recently reported sequences of novel pestiviruses. As a result, we propose to establish eight additional species (Pestivirus L, Pestivirus $M$, Pestivirus N, Pestivirus $O$, Pestivirus $P$, Pestivirus $Q$, Pestivirus $R$, and Pestivirus $S$ ), expanding the number of pestivirus species to 19 . Most of the new viruses are genetically very distinct from members of the previously approved species Pestivirus $A$ through Pestivirus K. Thus, the calculation of $\mathrm{p}$-distances between complete coding nucleotide sequences and between complete viral polyprotein sequences is very useful for species demarcation. When analyzing p-distances based on genome sequences, the identification of genetic insertions and other genomic rearrangements as well as manual editing can be required [26]; such genomic alterations frequently occur in the genomes of cytopathic pestiviruses but may also be present in the genomes of non-cp pestiviruses [49]. In this study, phylogenetic analysis of a highly conserved part of NS5B (NS5B ${ }_{3312-3837}$ ) was consistent with that observed for

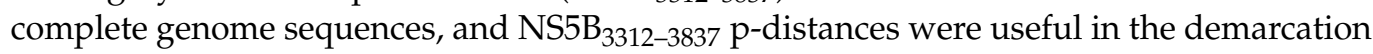

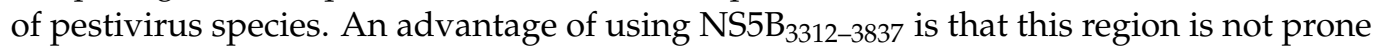
to large-scale insertion or deletion and so no additional editing of sequences is required. However, analysis of this region is less useful in demarcating CSFV (Pestivirus C), TSV (Pestivirus N), and ovIT PeV (Pestivirus O).

The genetic and antigenic similarity of CSFV, TSV, and ovIT isolates complicates the demarcation of species in the genus Pestivirus. A close genetic and antigenic relationship 
between the ovIT isolates (Pestivirus $O$ ) and CSFV (Pestivirus $C$ ) has been recently reported and may cause problems in CSF molecular and serological diagnosis if the ovine pestiviruses are ever shown to be able to infect porcine hosts under natural conditions [50,51]. Genetic analysis based on p-distances was not suited to demarcate the species Pestivirus $N$ and Pestivirus $O$, which are closely related to each other and to CSFV (Pestivirus $C$ ) as calculated distances lie in a range that do not show a clear affiliation. Instead, topology of phylogenetic trees, host range, and the clinical signs are considered the most important criteria. Phylogenetic trees of cds, polyprotein, and conserved NS5B sequences clearly showed that ovIT PeV (Pestivirus O) shares a common branch with CSFV (Pestivirus C) but is distinct from CSFV (Figure 1).

Consequently, the topology of phylogenetic trees provides a strong argument to recognize ovIT isolates and TSV as members of two different species being also different to the established species Pestivirus $C$. However, it can be speculated that further pestiviruses may exist that will fill up the gaps between these branches in the phylogenetic tree. Furthermore, a clear discrimination to CSFV (Pestivirus $C$ ) might become challenging if viruses similar to TSV (Pestivirus N) and ovIT PeV (Pestivirus $O$ ) are found to cross the species barrier and efficiently infect and replicate in porcine hosts under natural conditions. In this context, it is important to emphasize that, despite close genetic and antigenic relatedness of CSFV (Pestivirus C), TSV (Pestivirus N), and ovIT PeV (Pestivirus O), clear differences exist in host specificity and clinical disease induced by both ruminant pestiviruses in comparison to CSFV (Pestivirus C) [39,51]. TSV (Pestivirus N) was discovered in 1995 and since that time, no natural infections have been reported in porcine hosts. Moreover, despite retrospective evidence for the presence of ovIT PeV (Pestivirus O) in small ruminants in the late 1990s, these viruses have also never been found in pigs. Two recent studies demonstrated that these ruminant pestiviruses are able to infect pigs under experimental conditions, but viral replication was very limited. In addition, replication of TSV (Pestivirus N) on porcine cells was demonstrated to be rather inefficient in vitro. Moreover, these ruminant pestiviruses were either not able to induce disease (in the case of TSV) or induced only mild, unspecific clinical signs and pathological alterations (in the case of ovIT isolates) that resemble the outcome of horizontal infections of pigs with other ruminant pestiviruses, e.g., BVDV-1 (Pestivirus A) and BDV (Pestivirus D) [39,51].

Taken together, the topology of phylogenetic trees, host specificity, and induced clinical signs support the proposed classification of TSV and ovIT virus isolates as two novel pestivirus species (Pestivirus $N$ and Pestivirus $O$ ). In addition, regulatory aspects implicated in the control of CSF require a clear differentiation of CSFV from other pestiviruses and emphasize the importance of surveillance as well as molecular, serological, and biological characterization of established and novel pestiviruses circulating in domestic and wild animals.

Author Contributions: Conceptualization, A.P. and P.B.; methodology, A.P., P.B. and D.B.S.; writingoriginal draft preparation, A.P.; writing - review and editing, P.B. and D.B.S.; visualization, A.P. All authors have read and agreed to the published version of the manuscript.

Funding: This research received no external funding. DBS was supported by grant WT108418AIA from the Wellcome Trust.

Institutional Review Board Statement: Not applicable.

Informed Consent Statement: Not applicable.

Conflicts of Interest: The authors declare no conflict of interest.

\section{References}

1. Simmonds, P.; Becher, P.; Bukh, J.; Gould, E.A.; Meyers, G.; Monath, T.; Muerhoff, S.; Pletnev, A.; Rico-Hesse, R.; Smith, D.B.; et al. ICTV Virus Taxonomy Profile: Flaviviridae. J. Gen. Virol. 2017, 98, 2-3. [CrossRef] [PubMed]

2. Houe, H. Economic impact of BVDV infection in dairies. Biologicals 2003, 31, 137-143. [CrossRef]

3. Moennig, V.; Becher, P. Pestivirus control programs: How far have we come and where are we going? Anim. Health Res. Rev. 2015, 16, 83-87. [CrossRef] [PubMed] 
4. Becher, P.; König, M.; Paton, D.J.; Thiel, H.J. Further characterization of Border disease virus isolates: Evidence for the presence of more than three species within the genus Pestivirus. Virology 1995, 209, 200-206. [CrossRef] [PubMed]

5. Becher, P.; Orlich, M.; Shannon, A.D.; Horner, G.; Konig, M.; Thiel, H.J. Phylogenetic analysis of pestiviruses from domestic and wild ruminants. J. Gen. Virol. 1997, 78, 1357-1366. [CrossRef] [PubMed]

6. Liu, L.; Xia, H.; Wahlberg, N.; Belak, S.; Baule, C. Phylogeny, classification and evolutionary insights into pestiviruses. Virology 2009, 385, 351-357. [CrossRef]

7. Schirrmeier, H.; Strebelow, G.; Depner, K.; Hoffmann, B.; Beer, M. Genetic and antigenic characterization of an atypical pestivirus isolate, a putative member of a novel pestivirus species. J. Gen. Virol. 2004, 85, 3647-3652. [CrossRef]

8. Neill, J.D.; Ridpath, J.F.; Fischer, N.; Grundhoff, A.; Postel, A.; Becher, P. Complete genome sequence of pronghorn virus, a pestivirus. Genome Announc. 2014, 2, e00575-14. [CrossRef]

9. Vilcek, S.; Ridpath, J.F.; Van Campen, H.; Cavender, J.L.; Warg, J. Characterization of a novel pestivirus originating from a pronghorn antelope. Virus Res. 2005, 108, 187-193. [CrossRef]

10. Kirkland, P.D.; Frost, M.J.; Finlaison, D.S.; King, K.R.; Ridpath, J.F.; Gu, X. Identification of a novel virus in pigs-Bungowannah virus: A possible new species of pestivirus. Virus Res. 2007, 129, 26-34. [CrossRef]

11. Becher, P.; Schmeiser, S.; Oguzoglu, T.C.; Postel, A. Complete genome sequence of a novel pestivirus from sheep. J. Virol. 2012, 86, 11412. [CrossRef] [PubMed]

12. Postel, A.; Schmeiser, S.; Oguzoglu, T.C.; Indenbirken, D.; Alawi, M.; Fischer, N.; Grundhoff, A.; Becher, P. Close relationship of ruminant pestiviruses and classical swine fever virus. Emerg. Infect. Dis. 2015, 21, 668-672. [CrossRef] [PubMed]

13. Sevik, M. Genomic characterization of pestiviruses isolated from bovine, ovine and caprine foetuses in turkey: A potentially new genotype of Pestivirus I species. Transbound. Emerg. Dis. 2020, 8, 417-442.

14. Hause, B.; Collin, E.A.; Peddireddi, L.; Yuan, F.; Chen, Z.; Hesse, R.A.; Gauger, P.C.; Clement, T.; Fang, Y.; Anderson, G. Discovery of a novel putative atypical porcine pestivirus in pigs in the United States. J. Gen. Virol. 2015, 96, 2994-2998. [CrossRef] [PubMed]

15. Postel, A.; Hansmann, F.; Baechlein, C.; Fischer, N.; Alawi, M.; Grundhoff, A.; Derking, S.; Tenhundfeld, J.; Pfankuche, V.M.; Herder, V.; et al. Presence of atypical porcine pestivirus (APPV) genomes in newborn piglets correlates with congenital tremor. Sci. Rep. 2016, 6, 27735. [CrossRef] [PubMed]

16. Postel, A.; Meyer, D.; Cagatay, G.N.; Feliziani, F.; De Mia, G.M.; Fischer, N.; Grundhoff, A.; Milicevic, V.; Deng, M.C.; Chang, C.Y.; et al. High abundance and genetic variability of atypical porcine pestivirus in pigs from Europe and Asia. Emerg. Infect. Dis. 2017, 23, 2104-2107. [CrossRef]

17. Arruda, B.L.; Arruda, P.H.; Magstadt, D.R.; Schwartz, K.J.; Dohlman, T.; Schleining, J.A.; Patterson, A.R.; Visek, C.A.; Victoria, J.G. Identification of a divergent lineage porcine pestivirus in nursing piglets with congenital tremors and reproduction of disease following experimental inoculation. PLoS ONE 2016, 11, e0150104. [CrossRef]

18. de Groof, A.; Deijs, M.; Guelen, L.; van Grinsven, L.; van Os-Galdos, L.; Vogels, W.; Derks, C.; Cruijsen, T.; Geurts, V.; Vrijenhoek, M.; et al. Atypical porcine pestivirus: A possible cause of congenital tremor type A-II in newborn piglets. Viruses $2016,8,271$. [CrossRef]

19. Becher, P.; Moennig, V.; Tautz, N. Bovine viral diarrhea, border disease, and classical swine fever viruses (Flaviviridae). In Encyclopedia of Virology (Fourth Edition); Bamford, D.H., Zuckerman, M., Eds.; Academic Press Amsterdam: Oxford, Cambridge, 2021; Volume 2, pp. 153-164.

20. Firth, C.; Bhat, M.; Firth, M.A.; Williams, S.H.; Frye, M.J.; Simmonds, P.; Conte, J.M.; Ng, J.; Garcia, J.; Bhuva, N.P.; et al. Detection of zoonotic pathogens and characterization of novel viruses carried by commensal Rattus norvegicus in New York City. mBio 2014, 5, e01933-14. [CrossRef]

21. Gao, W.H.; Lin, X.D.; Chen, Y.M.; Xie, C.G.; Tan, Z.Z.; Zhou, J.J.; Chen, S.; Holmes, E.C.; Zhang, Y.Z. Newly identified viral genomes in pangolins with fatal disease. Virus Evol. 2020, 6, veaa020. [CrossRef]

22. Jo, W.K.; van Elk, C.; van de Bildt, M.; van Run, P.; Petry, M.; Jesse, S.T.; Jung, K.; Ludlow, M.; Kuiken, T.; Osterhaus, A. An evolutionary divergent pestivirus lacking the $\mathrm{N}^{\text {pro }}$ gene systemically infects a whale species. Emerg. Microbes Infect. 2019, 8 , 1383-1392. [CrossRef]

23. Wu, Z.; Liu, B.; Du, J.; Zhang, J.; Lu, L.; Zhu, G.; Han, Y.; Su, H.; Yang, L.; Zhang, S.; et al. Discovery of diverse rodent and bat pestiviruses with distinct genomic and phylogenetic characteristics in several Chinese provinces. Front. Microbiol. $2018,9,2562$. [CrossRef]

24. Wu, Z.; Lu, L.; Du, J.; Yang, L.; Ren, X.; Liu, B.; Jiang, J.; Yang, J.; Dong, J.; Sun, L.; et al. Comparative analysis of rodent and small mammal viromes to better understand the wildlife origin of emerging infectious diseases. Microbiome 2018, 6, 178. [CrossRef]

25. Wu, Z.; Ren, X.; Yang, L.; Hu, Y.; Yang, J.; He, G.; Zhang, J.; Dong, J.; Sun, L.; Du, J.; et al. Virome analysis for identification of novel mammalian viruses in bat species from Chinese provinces. J. Virol. 2012, 86, 10999-11012. [CrossRef]

26. Smith, D.B.; Meyers, G.; Bukh, J.; Gould, E.A.; Monath, T.; Scott Muerhoff, A.; Pletnev, A.; Rico-Hesse, R.; Stapleton, J.T.; Simmonds, P.; et al. Proposed revision to the taxonomy of the genus Pestivirus, family Flaviviridae. J. Gen. Virol. 2017, 98, 2106-2112. [CrossRef] [PubMed]

27. ICTV Report. Flaviviridae, Genus: Pestivirus. Available online: https://talk.ictvonline.org/ictv-reports/ictv_online_report/ positive-sense-rna-viruses/w/flaviviridae/361/genus-pestivirus (accessed on 2 January 2021).

28. Deng, R.; Brock, K.V. Molecular cloning and nucleotide sequence of a pestivirus genome, noncytopathic bovine viral diarrhea virus strain SD-1. Virology 1992, 191, 867-869. [CrossRef] 
29. Collett, M.S.; Larson, R.; Gold, C.; Strick, D.; Anderson, D.K.; Purchio, A.F. Molecular cloning and nucleotide sequence of the pestivirus bovine viral diarrhea virus. Virology 1988, 165, 191-199. [CrossRef]

30. Ridpath, J.F.; Bolin, S.R. The genomic sequence of a virulent bovine viral diarrhea virus (BVDV) from the type 2 genotype: Detection of a large genomic insertion in a noncytopathic BVDV. Virology 1995, 212, 39-46. [CrossRef]

31. Ruggli, N.; Tratschin, J.D.; Mittelholzer, C.; Hofmann, M.A. Nucleotide sequence of classical swine fever virus strain Alfort/187 and transcription of infectious RNA from stably cloned full-length cDNA. J. Virol. 1996, 70, 3478-3487. [CrossRef] [PubMed]

32. Becher, P.; Shannon, A.D.; Tautz, N.; Thiel, H.J. Molecular characterization of Border disease virus, a pestivirus from sheep. Virology 1994, 198, 542-551. [CrossRef]

33. Becher, P.; Fischer, N.; Grundhoff, A.; Stalder, H.; Schweizer, M.; Postel, A. Complete genome sequence of bovine pestivirus strain PG-2, a second member of the tentative pestivirus species giraffe. Genome Announc. 2014, 2, e00376-14. [CrossRef] [PubMed]

34. Becher, P.; Orlich, M.; Kosmidou, A.; König, M.; Baroth, M.; Thiel, H.J. Genetic diversity of pestiviruses: Identification of novel groups and implications for classification. Virology 1999, 262, 64-71. [CrossRef]

35. Liu, L.; Kampa, J.; Belak, S.; Baule, C. Virus recovery and full-length sequence analysis of atypical bovine pestivirus TH/04_Khonkaen. Vet. Microbiol. 2009, 138, 62-68. [CrossRef] [PubMed]

36. Kumar, S.; Stecher, G.; Li, M.; Knyaz, C.; Tamura, K. MEGA X: Molecular evolutionary genetics analysis across computing platforms. Mol. Biol. Evol. 2018, 35, 1547-1549. [CrossRef]

37. Sameroff, S.; Tokarz, R.; Charles, R.A.; Jain, K.; Oleynik, A.; Che, X.; Georges, K.; Carrington, C.V.; Lipkin, W.I.; Oura, C. Viral diversity of tick species parasitizing cattle and dogs in Trinidad and Tobago. Sci. Rep. 2019, 9, 10421. [CrossRef] [PubMed]

38. Ciulli, S.; Purpari, G.; Agnello, S.; Di Marco, P.; Di Bella, S.; Volpe, E.; Mira, F.; de Aguiar Saldanha Pinheiro, A.C.; Vullo, S.; Guercio, A. Evidence for Tunisian-like pestiviruses presence in small ruminants in Italy since 2007. Transbound. Emerg. Dis. 2017, 64, 1243-1253. [CrossRef] [PubMed]

39. Meyer, D.; Postel, A.; Wiedemann, A.; Cagatay, G.N.; Becher, P. Comparatative analysis of Tunisian sheep-like pestivirus, Bungowannah virus and Border disease virus infection in the porcine host. Viruses 2021, in press.

40. Lamp, B.; Schwarz, L.; Hogler, S.; Riedel, C.; Sinn, L.; Rebel-Bauder, B.; Weissenbock, H.; Ladinig, A.; Rumenapf, T. Novel pestivirus species in pigs, Austria, 2015. Emerg. Infect. Dis. 2017, 23, 1176-1179. [CrossRef]

41. Sozzi, E.; Lavazza, A.; Gaffuri, A.; Bencetti, F.C.; Prosperi, A.; Lelli, D.; Chiapponi, C.; Moreno, A. Isolation and full-length sequence analysis of a pestivirus from aborted lamb fetuses in Italy. Viruses 2019, 11, 744. [CrossRef]

42. Kiesler, A.; Seitz, K.; Schwarz, L.; Buczolich, K.; Petznek, H.; Sassu, E.; Durlinger, S.; Hogler, S.; Klang, A.; Riedel, C.; et al. Clinical and serological evaluation of LINDA virus infections in post-weaning piglets. Viruses 2019, 11, 975. [CrossRef]

43. Cagatay, G.N.; Meyer, D.; Wendt, M.; Becher, P.; Postel, A. Characterization of the humoral immune response induced after infection with atypical porcine pestivirus (APPV). Viruses 2019, 11, 880. [CrossRef]

44. Thabti, F.; Fronzaroli, L.; Dlissi, E.; Guibert, J.M.; Hammami, S.; Pepin, M.; Russo, P. Experimental model of Border disease virus infection in lambs: Comparative pathogenicity of pestiviruses isolated in France and Tunisia. Vet. Res. 2002, 33, 35-45. [CrossRef] [PubMed]

45. Thabti, F.; Letellier, C.; Hammami, S.; Pepin, M.; Ribiere, M.; Mesplede, A.; Kerkhofs, P.; Russo, P. Detection of a novel Border disease virus subgroup in Tunisian sheep. Arch. Virol. 2005, 150, 215-229. [CrossRef] [PubMed]

46. Dubois, E.; Russo, P.; Prigent, M.; Thiery, R. Genetic characterization of ovine pestiviruses isolated in France, between 1985 and 2006. Vet. Microbiol. 2008, 130, 69-79. [CrossRef]

47. Martin, C.; Duquesne, V.; Adam, G.; Belleau, E.; Gauthier, D.; Champion, J.L.; Saegerman, C.; Thiery, R.; Dubois, E. Pestiviruses infections at the wild and domestic ruminants interface in the French Southern Alps. Vet. Microbiol. 2015, 175, 341-348. [CrossRef] [PubMed]

48. Hurtado, A.; Garcia-Perez, A.L.; Aduriz, G.; Juste, R.A. Genetic diversity of ruminant pestiviruses from Spain. Virus Res. 2003, 92, 67-73. [CrossRef]

49. Becher, P.; Tautz, N. RNA recombination in pestiviruses: Cellular RNA sequences in viral genomes highlight the role of host factors for viral persistence and lethal disease. RNA Biol. 2011, 8, 216-224. [CrossRef] [PubMed]

50. Casciari, C.; Sozzi, E.; Bazzucchi, M.; Moreno Martin, A.M.; Gaffuri, A.; Giammarioli, M.; Lavazza, A.; De Mia, G.M. Serological relationship between a novel ovine pestivirus and classical swine fever virus. Transbound. Emerg. Dis. 2020, 67, 1406-1410. [CrossRef]

51. Bohorquez, J.A.; Sozzi, E.; Wang, M.; Alberch, M.; Abad, X.; Gaffuri, A.; Lelli, D.; Rosell, R.; Perez, L.J.; Moreno, A.; et al. The new emerging ovine pestivirus can infect pigs and confers strong protection against classical swine fever virus. Transbound. Emerg. Dis. 2021. In press. [CrossRef] 